\title{
LEGISLAÇÃO AMBIENTAL BRASILEIRA E O DESENVOLVIMENTO DA ATIVIDADE SUINÍCOLA COM ALTERNATIVAS PARA O GERENCIAMENTO AMBIENTAL ADEQUADO DOS DEJETOS ANIMAIS
}

\author{
STRADA, Vanessa Cristina do Nascimento Martins ${ }^{1}$ \\ LIMA, Erico da Silva ${ }^{2}$ \\ SOTO, Francisco Rafael Martins ${ }^{3}$ \\ COSTA, Adriano Adelson ${ }^{4}$ \\ SANTANA, Barbara Leticia Lima ${ }^{5}$
}

RESUMO: A suinocultura brasileira é uma atividade econômica de grande destaque no cenário nacional e internacional. No entanto, devido a muitas aplicações irregulares e descuidadas de todo o processo de produção suína, se teve também um crescimento mundial no potencial poluidor da suinocultura, sendo necessário que sua implantação e desenvolvimento sejam orientados por instrumentos legais e regulares. O presente estudo de revisão de literatura teve como objetivo promover uma análise da aplicação da legislação ambiental brasileira no desenvolvimento da suinocultura, e caracterizar as alternativas voltadas para a promoção de sustentabilidade na cadeia produtiva desta atividade.

Palavras-chave: Suinocultura. Resíduos animais. Poluição. Cadeia produtiva

\section{BRAZILIAN ENVIRONMENTAL LEGISLATION AND THE DEVELOPMENT OF SWINE BREEDING ACTIVITY WITH ALTERNATIVES TO THE APPROPRIATE ENVIRONMENTALLY MANAGEMENT OF ANIMAL WASTE}

SUMMARY: The Brazilian swine breeding is an economic activity with a great national and international highlight. Although, many irregular and reckless application of the whole swine production process, there has also been a worldwide growth in the polluting potential of swine and this implementation, and development must be guided by legal and regulatory instruments. This literature review study aims to an analysis of the Brazilian Ennvironmental Legisllation implementation on swine breeding development and lecture on the alternatives focused on the promotion of sustainability of animal supply and their activities.

Keywords: Swine-breeding. Animal wastes. Pollution. Animal supply.

\section{INTRODUÇÃO}

A suinocultura é uma atividade econômica que cresceu significativamente nas últimas décadas, e que vêm ganhando destaque na cadeia da agroindústria nacional e internacional (VIANCELLI et al.,

\footnotetext{
${ }^{1}$ Biomédica. Mestre pelo Programa de Mestrado Profissional em Saúde Ambiental, Centro Universitário das Faculdades Metropolitanas Unidas (FMU), São Paulo, Brazil

${ }^{2}$ Doutor em Zootecnia. Professor no Programa de Mestrado Profissional em Saúde Ambiental, Centro Universitário das Faculdades Metropolitanas Unidas (FMU), São Paulo, Brazil

${ }^{3}$ Doutor em Epidemiologia Experimental Aplicada às Zoonoses. Professor do Instituto Federal de São Paulo Campus São Roque, SP, Brazil.

${ }^{4}$ Tecnólogo em Gestão Ambiental. Mestre pelo Programa de Mestrado Profissional em Saúde Ambiental, Centro Universitário das Faculdades Metropolitanas Unidas (FMU), São Paulo, Brazil

${ }^{5}$ Bióloga pelo Centro Universitário das Faculdades Metropolitanas Unidas (FMU), São Paulo, Brazil
} 
2013; COSTA; SOTO, 2018). O crescimento populacional, a urbanização e o aumento da renda nos países desenvolvidos e em desenvolvimento estão estimulando um aumento no consumo dos produtos de origem animal (MIRANDA, 2007; SANTOS et al., 2015). Em resposta a demanda crescente dos consumidores, a produção mundial de carne suína aumentou aproximadamente $75 \%$ entre 1980 e 2001, consolidando-se como a mais importante fonte de proteína animal no mundo (CIAS, 2015; OCDE, 2015).

O Brasil também acompanhou esse crescimento, atualmente o consumo per capita anual de carne suína é de 14,4 Kg, e a produção de carne suína passou de 3,64 milhões de toneladas em 2015 para 3,75 milhões de toneladas em 2017, com um aumento de 2,6\% (ABPA, 2018).

O crescimento no consumo de carne suína, com consequente aumento nas exportações e na produção fez com que a suinocultura se tornasse uma atividade produtiva de grande importância no cenário econômico nacional (CARIS et al., 2008). E também provocou mudanças estruturais nos sistemas de produção, já que uma demanda elevada exige uma produção mais eficiente. Os sistemas passaram de uma pecuária familiar, baseada na criação de poucos animais, para um sistema tecnificado, sustentado na criação de muitos animais em confinamento, com maior geração de proteína animal, todavia com um significativo aumento no volume de resíduos (ABREU; OLIVEIRA, 2009; OCDE, 2015).

Os resíduos originados na criação de suínos são considerados altamente poluidores, pois apresentam altas concentrações de matéria orgânica; sólidos suspensos; nutrientes, principalmente fósforo e nitrogênio; bactérias potencialmente patogênicas, como por exemplo, Escherichia coli e Salmonella sp. e alguns protozoários (VIANCELLI et al., 2013; SÁ et al., 2014; OLIVEIRA et al., 2014).

Sendo assim, quando não tratados e manejados de forma eficiente, levando em consideração os padrões estabelecidos pela Legislação Ambiental em vigor, colocam em risco a sustentabilidade da cadeia produtiva, interferindo na expansão da suinocultura e na economia do país (CARIS et al., 2008).

A utilização de um tratamento adequado para os resíduos promove uma redução no seu poder de poluição, atingindo concentrações de nutrientes e micro-organismos dentro dos padrões exigidos pelas leis ambientais e ainda permite sua utilização, por exemplo, como fertilizantes na produção de alimentos, na melhora das condições físicas, químicas e biológicas do solo, e na geração de energia (MIRANDA et al., 2012; SANTOS et al., 2014).

Porém, o manejo, armazenamento, distribuição, tratamento ou disposição no solo de forma adequada, aumenta os custos da atividade (BRANDÃO et al., 2000), fazendo com que muitos produtores ignorem o problema ambiental, e lancem seus resíduos de alto potencial poluidor no ambiente. A água, por exemplo, é um dos abióticos que sofre mais influência negativa quando se trata dos resíduos gerados pelo processo, tanto quando se fala de poluição dos despejos, quando falamos do consumo excessivo para a qualidade de vida destes animais. A poluição do solo também possui uma relevância no quesito de poluição dos dejetos, sendo poluído principalmente por esterco, urina, resíduos de ração e água. Antigamente, os valores de poluição do solo não eram considerados ameaçadores a qualidade, mas devido a modernização do sistema de produção, se tornou uma grande preocupação para a qualidade ambiental.

Um suíno produz em média sete litros de dejetos por dia (PERDOMO, 1998), com substâncias que se tornam extremamente tóxicos em alta concentração, como o nitrogênio $(\mathrm{N})$, o fósforo $(\mathrm{P})$ e metais pesados como o Zinco $(\mathrm{Zn})$, e cobre $(\mathrm{Cu})$, e uma variedade de micro-organismos patógenos. O deságue desses dejetos em recursos hídricos com essa quantidade de substâncias, gera um desequilíbrio no ambiente, desencadeando processos como a eutrofização, onde os corpos d'água atingem um alto nível de concentração de nutrientes, e o aumento de organismos prejudiciais, tanto à biodiversidade local, quanto aos seres humanos que vivem ao redor, podendo ser a chave para doenças como leptospirose, tularemia, febre aftosa, peste suína, e o mais comum para os seres humanos, as verminoses e alergias.

$\mathrm{O}$ ar também sofre com os impactos causados pela suinocultura, graças à emissão de gases 
através destes resíduos. Um gás que pode ser encontrado é o carbamato de amônio $\left(\mathrm{NH}_{2} \mathrm{COONH}_{4}\right)$ que, segundo Lopes, Filho e Alves (2013), possui a capacidade de se associar aos gases de amônia $\left(\mathrm{NH}_{3}\right)$ e dióxido de carbono $\left(\mathrm{CO}_{2}\right)$, causando irritações, alergias e distúrbio neurológico nos seres humanos, e causando efeitos negativos também na atmosfera, como chuvas ácidas e o efeito estufa.

Estudos na área da suinocultura são realizados todos os anos com o enfoque de encontrar os problemas de suas aplicações, desde sua origem até o resultado final de cada aspecto negativo. Nesse sentido é de extrema importância que haja o desenvolvimento de novas tecnologias e novos projetos na área, onde vise a saúde ambiental dos lugares de aplicação e seus arredores, através de estudos e planos de melhorias, relatórios de impacto e meios de implantação em equilíbrio, onde por fim se viabilize a cadeia produtiva suinícola. Baseado neste cenário, este estudo teve como objetivo principal promover através de um estudo de revisão de literatura, uma análise dos instrumentos legais da legislação ambiental brasileira que são aplicáveis no desenvolvimento da suinocultura, e caracterizar as alternativas que contribuem para a sustentabilidade na cadeia produtiva.

\section{SUINOCULTURA NO BRASIL E NO MUNDO}

Os principais produtores de carne suína de acordo com os dados da ABPA (2018) no ano de 2017 são China (53,4 milhões de toneladas), União Européia (23,7 milhões de toneladas) e Estados Unidos (11,6 milhões de toneladas), seguidos pelo Brasil que apresenta uma produção de 3,76 milhões de toneladas. Ainda, segundo dados da ABPA (2018), o Brasil também ocupa a quarta posição dentre os países exportadores de carne suína, com um total de 697 mil toneladas exportadas em 2017.

As exportações brasileiras no primeiro trimestre de 2016 (139,713 mil toneladas) registraram melhor desempenho do que as exportações do mesmo período de 2015 (76.394 toneladas), porém o número de cabeças de suínos abatidas manteve-se no mesmo patamar (10,06 milhões) reduzindo a disponibilidade interna de carne suína, uma queda de cerca de 1,5\% referente ao mesmo período do ano anterior (IBGE, 2017).

Dentre as regiões brasileiras, a região Sul se destaca com o maior número de abates de suínos no primeiro trimestre de 2016 (66,3\%), seguida pelas regiões Sudeste (18,3\%) e Centro-Oeste (14,3\%). Em relação às exportações, comparando o primeiro trimestre de 2016 com o mesmo período de 2015, destacou-se Santa Catarina como o principal estado exportador de carne suína, com um aumento de 74,5\% no volume exportado. Outros estados, foram Rio Grande do Sul e Paraná, com um aumento no volume exportado, de respectivamente, 62,8\% e 96,3\%. Mato Grosso, Goiás e Minas Gerais também tiveram um aumento do volume exportado, enquanto que, em São Paulo e Mato Grosso do Sul ocorreu redução nas exportações (IBGE, 2017).

A expansão da demanda global de carne, associada às projeções de um aumento de $20 \%$ da produção mundial de alimentos em 2020 e, o ciclo relativamente curto de produção, demonstra que o setor suíno continuará a ter papel importante na economia nos próximos anos (OCDE, 2015).

\section{ALTERAÇÃO DA ESTRUTURA DE PRODUÇÃO, AUMENTO NA GERAÇÃO DE DEJETOS E POLUIÇÃO AMBIENTAL}

Nas últimas décadas os modelos de produção agropecuária priorizaram as necessidades econômicas, investindo em técnicas para aumentar a produtividade e o lucro, sem levar em consideração a sustentabilidade do sistema (SPIES, 2009). Os produtores para manterem-se competitivos no mercado da suinocultura, minimizaram os custos com a produção, tirando o máximo proveito da matéria-prima, 
aperfeiçoaram a produtividade e, mantiveram os padrões de qualidade de matéria prima cada vez mais exigidos pelo mercado consumidor (MIRANDA, 2007). O resultado dessa busca, por melhores desempenhos econômicos, foi o surgimento de uma suinocultura moderna caracterizada pela produção tecnificada de suínos para abate e ou reprodução (SESTI, SOBESTIANSKY, 1998).

O bom sinergismo entre a genética e a nutrição, levando-se em consideração outros aspectos do processo produtivo, tais como, instalações, ambiente adverso, manejo, patógenos, recursos humanos e assistência técnica, associados a constantes estudos para modernização, adaptação e melhora na qualidade dos fatores mencionados, são fundamentais para o sucesso da produção suinícola moderna (SESTI, SOBESTIANSKY, 1998; ZANOTELLI, 2002).

A necessidade por produtos de mais qualidade, porém sem aumentos significativos nos preços repassados a população, incrementou a competitividade e culminou com o surgimento das agroindústrias que realizam com os produtores um sistema de integração, no qual as indústrias fornecem ao produtor os animais, a ração e assistência técnica; e os produtores participam fornecendo as instalações e mão de obra (ZANOTELLI, 2002; SANTOS, 2015).

A modernização da suinocultura, os avanços tecnológicos no sistema produtivo e o surgimento destas agroindústrias, fez com que muitos produtores menos competitivos fossem excluídos do mercado e, os demais, acabaram adotando um sistema de confinamento altamente especializado, com a criação de um número maior de animais em áreas cada vez menores (SPIES, 2009; URBINATI; OLIVEIRA, 2013).

Um dos principais problemas causado por esse sistema de criação intensivo é o volume de resíduos produzidos diariamente (MORAES; PAULA, 2004). Em média, um suíno produz 5,80 Kg de dejetos (fezes e urina) por dia (BELI et al., 2010). Levando em consideração a alta densidade de animais por metro quadrado, e que fazem parte desses resíduos outros constituintes, tais como restos de ração, restos de animais (pelos e células mortas), água utilizada na lavagem das instalações e perdida pelos bebedouros, produtos para limpeza, entre outros, o volume final gerado será altamente significativo (MORAES; PAULA, 2004).

Até a década de 1970 os resíduos não preocupavam, pois a concentração de animais era pequena e os solos tinham a capacidade de assimilar as cargas orgânicas dos efluentes (SOUZA et al., 2009), mas atualmente, a carga orgânica presente nos efluentes suínos excede a capacidade de absorção de nutrientes pelo solo. O crescimento da suinocultura não foi acompanhado por um aumento nas áreas aptas a agricultura, gerando sobrecarga de resíduos por unidade de área nas propriedades (SÁ et al., 2014).

Devido às altas concentrações de matéria orgânica, sólidos suspensos, nutrientes, metais tóxicos e patógenos nas águas residuárias da suinocultura, sua disposição de forma indiscriminada no solo ou corpos d'agua, podem ocasionar sérios problemas ambientais e sanitários, ligados à depleção de oxigênio dissolvido, eutrofização, aumento de nitrato nas águas superficiais e subterrâneas, toxicidade por amônia a peixes, e problemas de saúde em virtude da presença de micro-organismos (FERNANDES; OLIVEIRA, 2006).

Além dos impactos ambientais nas águas e no solo, a degradação biológica dos resíduos da atividade suinícola gera gases tóxicos, tais como dióxido de carbono, metano, óxido nitroso e amônia, que ao serem lançados na atmosfera podem afetar a saúde, o desempenho dos suínos e a qualidade do ar (ANGONESE et al., 2007; COSTA; SOTO, 2018).

Entretanto, desde que armazenados e manejados de forma correta, os resíduos suínos podem ser aproveitados para várias funções, sendo utilizados na agricultura para adubação e fertirrigação, como alimento na piscicultura e na geração de bioenergia a partir do metano (SANTOS et al., 2015; COSTA; SOTO, 2018).

O manejo, armazenamento, distribuição, tratamento ou disposição no solo, de forma adequada 
aumenta os custos da atividade (BRANDÃO et al., 2000), fazendo com que muitos produtores ignorem o problema da poluição ambiental e lancem efluentes de alto potencial tóxico no ambiente. Nesse sentido, é de extrema importância que exista uma regulamentação e uma fiscalização eficiente, a fim de evitar os impactos ambientais negativos causados pela suinocultura, onde possibilita a realização de um parâmetro de comparação entre os métodos para a escolha da melhor alternativa da implantação, onde favoreça não só o meio ambiente, sendo o foco desses projetos de despoluição, como também a empresa ou o empreendedor que está financiando todo esse processo.

\section{LEGISLAÇÃO AMBIENTAL E SUINOCULTURA NO BRASIL}

O modelo produtivo adotado pela sociedade tem gerado impacto altamente catastrófico ao meio ambiente (CARIS et al., 2008). Nesse modelo, enquadra-se a suinocultura, que devido a sua produção intensiva e em confinamento leva a um aumento na poluição por resíduos, causando desequilíbrios ecológicos (CARVALHO et al., 2015).

A suinocultura é uma atividade altamente poluidora, sendo considerada pelos órgãos de controle ambiental como potencialmente causadora da degradação ambiental (CAMPOS et al., 2005; PALHARES; CALIJURI, 2006). Tem-se verificado nos últimos anos um aumento dos alertas de entidades oficiais e organizações de proteção ambiental relacionados aos danos causados pela suinocultura moderna ao ambiente natural (GOMES et al., 2014).

A noção de que o ambiente é fundamental para sobrevivência da espécie humana e perpetuação do planeta, além da percepção de que estamos em intensa relação com os outros seres vivos e os recursos naturais são recentes. A sociedade está começando a perceber que qualquer impacto que se relacione com o ambiente, terá consequências em sua qualidade de vida e na das próximas gerações (PALHARES, 2007). Por isso, é de extrema importância que as atividades econômicas levem em consideração a sustentabilidade de sua cadeia produtiva. Atualmente na agropecuária, o maior desafio é produzir carne de qualidade e em grande quantidade sem afetar adversamente o meio ambiente (KONZEN, 2006).

O caput do artigo 170 da Constituição Federal de 1988 afirma que a economia, baseada na valorização do trabalho humano e da livre iniciativa deve ser incentivada, a fim de permitir a todos uma existência digna, deve estar baseada em alguns princípios, dentre os quais se destaca a preservação do meio ambiente, inclusive sendo necessário um tratamento diferenciado conforme o impacto ambiental causado pela atividade econômica (Inciso VI). No caso da suinocultura, fica subentendido que a produção de carne deve ser estimulada, mas os impactos ambientais gerados pela atividade devem ser controlados, utilizando tratamentos para os resíduos gerados (BRASIL, 1988).

Devido ao comprometimento dos recursos naturais causado pela produção suinícola, entidades sociais vêm estimulando um desenvolvimento sustentável, a regulamentação ambiental e a definição de responsabilidades na cadeia produtiva (GOMES et al.., 2014).

Por ser potencialmente causadora de degradação ambiental, a criação de suínos necessita licenciamento ambiental para sua implantação e funcionamento. Dentre as normas legais utilizadas para fundamentar a determinação do licenciamento ambiental, estão o artigo 225 do capítulo VI da Constituição Federal de 1988, a Lei de Política Nacional do Meio Ambiente - PNMA (6938) de 1981, e as Resoluções do Conselho Nacional do Meio Ambiente - CONAMA, a 01 de 1986 e a 337 de 1997 (PALHARES, 2007).

Segundo o caput do artigo 225 da Constituição Federal de 1988: "Todos têm direito ao meio ambiente ecologicamente equilibrado, bem de uso comum do povo e essencial à sadia qualidade de vida, impondo-se ao Poder Público e à coletividade o dever de defendê-lo e preservá-lo para as presentes e 
futuras gerações" (BRASIL, 1988).

Segundo os Incisos IV, VI e VII do $\S 1^{\circ}$ deste artigo para assegurar esse direito, cabe ao Poder Público exigir, na forma da lei, estudo prévio do impacto ambiental, para instalação de obra ou atividade potencialmente causadora de significativa degradação do meio; promover educação ambiental e conscientização pública para a preservação do meio ambiente, e proteger a fauna e a flora, sendo vedadas em forma da lei as práticas que coloquem em risco sua função ecológica, provoquem a extinção de espécies ou submetam os animais a crueldade (BRASIL, 1988).

$\mathrm{O} \$ 3^{\circ}$ do mesmo artigo afirma que "as condutas e atividades consideradas lesivas ao meio ambiente sujeitarão os infratores, pessoas físicas ou jurídicas, a sanções penais e administrativas, independentemente da obrigação de reparar os danos causados" (BRASIL, 1988).

A PNMA, lei 6938 de 1981, em seu artigo $3^{\circ}$, define alguns conceitos importantes para entender porque a atividade suinícola é enquadrada como poluidora do ambiente.

I - meio ambiente, o conjunto de condições, leis, influências e interações de ordem física, química e biológica, que permite, abriga e rege a vida em todas as suas formas;

II - degradação da qualidade ambiental, a alteração adversa das características do meio ambiente;

III - poluição, a degradação da qualidade ambiental resultante de atividades que direta ou indiretamente: a) prejudiquem a saúde, a segurança e o bem-estar da população; b) criem condições adversas às atividades sociais e econômicas; c) afetem desfavoravelmente a biota; d) afetem as condições estéticas ou sanitárias do meio ambiente; e) lancem matérias ou energia em desacordo com os padrões ambientais estabelecidos;

IV - poluidor, a pessoa física ou jurídica, de direito público ou privado, responsável, direta ou indiretamente, por atividade causadora de degradação ambiental (BRASIL, 1981).

Relacionando o $\$ 3^{\circ}$ do artigo 225 da Constituição Federal de 1988 ao conceito de poluidor citado acima, fica claro que o lançamento dos efluentes da suinocultura em desacordo com os padrões ambientais estabelecidos, caracteriza o suinocultor como poluidor e, este, responderá pelo mesmo fato danoso em três esferas diferentes: penal, administrativa e civil (BRASIL, 1988).

Na PNMA estão definidos os órgãos responsáveis pela proteção e melhoria da qualidade ambiental, dentre os quais estão o Conselho Nacional do Meio Ambiente - CONAMA, com função consultiva e deliberativa; o Instituto Brasileiro do Meio Ambiente e dos Recursos Naturais Renováveis IBAMA, responsável pela execução das políticas e diretrizes nacionais do meio ambiente e; órgãos seccionais e locais, responsáveis respectivamente pelo controle e fiscalização das atividades capazes de provocar impacto ambiental em âmbito estadual e municipal (artigo 6º (BRASIL, 1981).

É a PNMA, em seu artigo $10^{\circ}$ que estabelece que a construção, instalação, ampliação e funcionamento de atividades, capazes de causar degradação ambiental, dependerão de prévio licenciamento ambiental (BRASIL, 1981).

A resolução 01 do CONAMA de 1986 em seu artigo $2^{\circ}$ define que o licenciamento das atividades modificadoras do meio ambiente dependerá de um estudo do impacto ambiental e respectivo relatório do impacto ambiental (RIMA), os quais deverão ser submetidos à aprovação do órgão estadual competente e do IBAMA (BRASIL, 1986).

Segundo o artigo $1^{\circ}$ desta resolução:

[...] considera-se impacto ambiental qualquer alteração das propriedades físicas, químicas e biológicas do meio ambiente, causada por qualquer forma de matéria ou energia resultante das atividades humanas que, direta ou indiretamente, afetam: I - a saúde, a segurança e o bem-estar da população; II - as atividades sociais e econômicas; 
III - a biota; IV - as condições estéticas e sanitárias do meio ambiente; V - a qualidade dos recursos ambientais." (BRASIL, 1986)

A suinocultura está entre essas atividades que geram potencial impacto ambiental negativo, já que os efluentes suínos levam à poluição dos solos agricultáveis e dos recursos hídricos (GOMES et al., 2014). Portanto, o licenciamento da suinocultura depende de um estudo prévio do impacto ambiental causado.

A resolução 237 do CONAMA de 1997 regulamenta os aspectos do licenciamento ambiental estabelecido pela PNMA, revisando-os e incorporando instrumentos de gestão ambiental, visando o desenvolvimento sustentável e a melhoria contínua. No artigo $1^{\circ}$ desta resolução são dadas algumas definições importantes:

I - Licenciamento Ambiental: procedimento administrativo pelo qual o órgão ambiental competente licencia a localização, instalação, ampliação e a operação de empreendimentos e atividades utilizadoras de recursos ambientais, consideradas efetiva ou potencialmente poluidoras ou daquelas que, sob qualquer forma, possam causar degradação ambiental, considerando as disposições legais e regulamentares e as normas técnicas aplicáveis ao caso.

II - Licença Ambiental: ato administrativo pelo qual o órgão ambiental competente, estabelece as condições, restrições e medidas de controle ambiental que deverão ser obedecidas pelo empreendedor, pessoa física ou jurídica, para localizar, instalar, ampliar e operar empreendimentos ou atividades utilizadoras dos recursos ambientais consideradas efetiva ou potencialmente poluidoras ou aquelas que, sob qualquer forma, possam causar degradação ambiental (BRASIL, 1997).

$\mathrm{O}$ artigo $2^{\circ}$ da mesma resolução afirma que:

A localização, construção, instalação, ampliação, modificação e operação de empreendimentos e atividades utilizadoras de recursos ambientais consideradas efetiva ou potencialmente poluidoras, bem como os empreendimentos capazes, sob qualquer forma, de causar degradação ambiental, dependerão de prévio licenciamento do órgão ambiental competente, sem prejuízo de outras licenças legalmente exigíveis. (BRASIL, 1997).

Em seu $\S 1^{\circ}$ está definido que a criação animal é uma dessas atividades que necessita de licenciamento ambiental (BRASIL, 1997).

Segundo o artigo $8^{\circ}$ da Resolução do CONAMA 237/97 são três licenças expedidas de acordo com a fase de licenciamento em que a atividade se encontra:

I - Licença Prévia (LP) - concedida na fase preliminar do planejamento do empreendimento ou atividade aprovando sua localização e concepção, atestando a viabilidade ambiental e estabelecendo os requisitos básicos e condicionantes a serem atendidos nas próximas fases de sua implementação;

II - Licença de Instalação (LI) - autoriza a instalação do empreendimento ou atividade de acordo com as especificações constantes dos planos, programas e projetos aprovados, incluindo as medidas de controle ambiental e demais condicionantes, da qual constituem motivo determinante;

III - Licença de Operação (LO) - autoriza a operação da atividade ou empreendimento, após a verificação do efetivo cumprimento do que consta das licenças anteriores, com as medidas de controle ambiental e condicionantes determinados para a operação (BRASIL, 1997).

No artigo $4^{\circ}$ desta Resolução fica definido que caberá ao IBAMA o licenciamento de atividades com significativo impacto ambiental nacional ou regional (quando envolve dois ou mais estados). No $\S 1^{\circ}$ 
deste artigo está descrito que o IBAMA fará o licenciamento ambiental levando em consideração estudos técnicos realizados previamente pelos órgãos ambientais dos estados e municípios, e quando couber, o parecer de outros órgãos competentes da União, dos estados, do Distrito Federal e dos municípios. Segundo o $\$ 2^{\circ}$ o IBAMA poderá delegar aos estados o licenciamento ambiental de atividade com significativo impacto ambiental de âmbito regional (localizados em mais de um munícipio ou unidades de conservação de domínio estadual ou do Distrito Federal), o que é enfatizado no artigo $5^{\circ}$. Por sua vez, no artigo $6^{\circ}$ fica definido que compete aos órgãos ambientais municipais, o licenciamento de atividades de impacto ambiental local e daquelas delegadas pelo Estado (BRASIL, 1997).

Além das normas técnicas vigentes, relacionadas ao licenciamento da atividade, como os resíduos da suinocultura são considerados sólidos, esta atividade deve estar de acordo com a Política Nacional dos Resíduos Sólidos (PNRS) (BRASIL, 2010a).

A lei 12.305 de 2010 em seu artigo $1^{\circ}$

[...] institui a Política Nacional de Resíduos Sólidos, dispondo sobre seus princípios, objetivos e instrumentos, bem como sobre as diretrizes relativas à gestão integrada e ao gerenciamento de resíduos sólidos, incluídos os perigosos, às responsabilidades dos geradores e do poder público e aos instrumentos econômicos aplicáveis. (BRASIL, 2010a).

No $\S 1^{\circ}$ deste artigo está definido que:

[...] estão sujeitas à observância desta lei as pessoas físicas ou jurídicas, de direito público ou privado, responsáveis, direta ou indiretamente, pela geração de resíduos sólidos e as que desenvolvam ações relacionadas à gestão integrada ou ao gerenciamento de resíduos sólidos. (BRASIL, 2010a).

O Decreto 7404/2010 (artigo $1^{\circ}$ caput) estabelece normas para execução da Política Nacional de Resíduos Sólidos, e em seu artigo $38^{\circ}$ afirma: “Os geradores de resíduos sólidos deverão adotar medidas que promovam a redução da geração dos resíduos, principalmente os resíduos perigosos, na forma prevista nos respectivos planos de resíduos sólidos e nas demais normas aplicáveis” (BRASIL, 2010b).

Caso as pessoas físicas ou jurídicas, como por exemplo, os suinocultores, atuem de forma contrária ou se omitam aos preceitos da PNRS ou de seu regulamento, estarão sujeitas às sanções previstas na lei (artigo 51º), em especial na lei 9605, de 12 de fevereiro de 1998 que dispõe sobre as sanções penais e administrativas derivadas de condutas e atividades lesivas ao meio ambiente (BRASIL, 1998).

No artigo $60^{\circ}$ da lei 9605 , é adotada como pena a detenção de um a seis meses, multa, ou ambas as penas para quem construir, reformar, ampliar, instalar ou colocar em funcionamento, em qualquer parte do território nacional, estabelecimentos, obras ou serviços potencialmente poluidores, sem licença ou autorização dos órgãos ambientais competentes, ou contrariando as normas legais e regulamentares pertinentes (BRASIL, 1998).

Os resíduos da suinocultura geralmente são manejados de forma inadequada, gerando efluentes com alta carga orgânica que quando lançados nos corpos d'água, ocasionam contaminação dos recursos hídricos da região (CARVALHO et al., 2015). Nesse sentido, a atividade deve estar de acordo com a Política Nacional dos Recursos Hídricos (PNRH) e com a Resolução do CONAMA 357 de 2005, que classifica os corpos de água superficiais de acordo com a qualidade requerida para os seus usos, fornecendo os padrões de todos os parâmetros em cada categoria de água (BRASIL, 1987; BRASIL, 2005). Essa resolução também estabelece condições e padrões do lançamento de efluentes em corpos de água receptores, mas essa parte foi revogada pela Resolução 430 de 2011 que agora desempenha 
esta função (BRASIL, 2011).

A PNRH (artigo $1^{\circ}$ ) baseia-se nos fundamentos de que a água é um bem de domínio público e um recurso natural limitado, dotado de valor econômico. Logo o uso da água com racionalidade na suinocultura é fundamental a fim de evitar aumento nos custos da criação, seja por um consumo abusivo ou pelo tratamento dos efluentes (PALHARES, 2007).

Um dos objetivos da PNRH (Inciso I, artigo $2^{\circ}$ ) é assegurar à atual e às futuras gerações a necessária disponibilidade de água, em padrões de qualidade adequados aos respectivos usos. A fim de cumprir esse objetivo, o lançamento em corpo d' água de esgotos e demais resíduos líquidos ou gasosos, tratados ou não, com o fim de sua diluição, transporte ou disposição final, deve ser outorgado pelo Poder Público (Inciso III, artigo $12^{\circ}$ ), evitando danos à qualidade da água. Caso a atividade não tenha a outorga, ou atue em desacordo com a mesma, o proprietário estará infringindo as normas estabelecidas no regulamento desta lei, e estará sujeito a penalidades (artigo 50²) (BRASIL, 1987).

A Resolução 430 de 2011 do CONAMA estabelece em seu artigo $3^{\circ}$, que os efluentes de qualquer fonte poluidora somente poderão ser lançados diretamente nos corpos receptores após o devido tratamento, e desde que obedeçam às condições, padrões e exigências dispostos nesta Resolução e em outras normas aplicáveis (BRASIL, 2011).

No sentido de regulamentar de forma mais específica à atividade suinícola, existe um conjunto de normas estaduais e municipais, subordinadas as federais, para adequar a produção de suínos de acordo com as condições econômicas e sociais de cada região do país, visando minimizar o impacto ambiental (PALHARES, 2008).

Os primeiros estados a desenvolverem normas, mais específicas para controlar o impacto ambiental gerado pelos resíduos da suinocultura, foram os da região Sul, já que lá está concentrada a maior produção de suínos do Brasil (PALHARES, 2008). Santa Catarina, devido ao problema ambiental gerado pelos efluentes da suinocultura na década de 90, desenvolveu o Termo de Ajustamento de Conduta (TAC) a fim de adequar as suinoculturas as legislações vigentes, fornecendo flexibilidade para que os produtores pudessem se adequar gradativamente as exigências estipuladas (MIRANDA, 2009). Atualmente, outros estados produtores também apresentam um conjunto de leis, decretos, instruções e deliberações normativas que determinam padrões para os resíduos líquidos e sólidos lançados no ambiente, além do licenciamento da atividade e das distâncias aplicadas a suinocultura (ALBUQUERQUE; WEYDMANN, 2015).

Existem órgãos estaduais e municipais específicos, responsáveis pelo estudo do impacto ambiental, etapas do licenciamento e fiscalização da atividade nas diferentes regiões do Brasil, tais como: Fundação do Meio Ambiente (FATMA) em Santa Catarina; Instituto Ambiental do Paraná (IAP); Instituto Estadual de Florestas (IEF) em Minas Gerais; Companhia Ambiental do Estado de São Paulo (CETESB); Superintendência Estadual do Meio Ambiente em Goiás, e Fundação Estadual do Meio Ambiente no Mato Grosso (ALBUQUERQUE; WEYDMANN, 2015).

Ao analisar toda a legislação ambiental citada anteriormente, referente aos impactos ambientais negativos que se enquadra a atividade suinícola, percebe-se que a legislação ambiental brasileira é altamente avançada em termos técnicos e jurídicos. Porém, isso não é suficiente para que os recursos naturais sejam preservados, e a atividade suinícola seja desenvolvida com equilíbrio ambiental (PALHARES, 2007), o que é devido a falta de formação adequada às pessoas envolvidas, falta de conhecimento técnico dos produtores, e ausência de controle ambiental por parte dos órgãos fiscalizadores (BELLI et al., 2001).

Infelizmente, no Brasil, poucas instalações suinícolas apresentam algum tipo de manejo de resíduos. Segundo Carvalho et al. (2015), dentre 37 granjas avaliadas no estado de São Paulo, 72,97\% 
foram consideradas como potencialmente geradoras de risco ambientais, principalmente pela disposição e destinação inadequada de seus efluentes e resíduos sólidos no ambiente.

Os efluentes que não são tratados e manejados de forma eficiente, levando em consideração os padrões estabelecidos pela Legislação Ambiental em vigor, colocam em risco a sustentabilidade da cadeia produtiva, interferindo na expansão da suinocultura e na economia do país (CARIS et al., 2008).

Nesse sentido, a educação ambiental torna-se fundamental, a fim de demonstrar aos produtores de suínos, que as normas visam contribuir para o avanço econômico da atividade, e não o contrário. Deve ficar claro para os produtores, que o não cumprimento destas normas, irá acarretar na degradação da qualidade ambiental com redução nos recursos naturais disponíveis, e no aumento dos custos na produção com grande impacto para a economia. (PALHARES, 2007).

Outro fato, a ser considerado, é que o foco das políticas públicas para a suinocultura, assim como para outras atividades, tem sido a proteção e a recuperação do ambiente, o que eleva os custos para os produtores. O mais adequado seria investir na prevenção dos riscos ambientais (PALHARES, 2008).

Nesse sentido, torna-se importante o estudo de opções para o tratamento dos resíduos, a fim de identificar e adotar alternativas para um manejo mais adequado, que ao mesmo tempo evitem a degradação da qualidade ambiental, e não sejam inviáveis do ponto de vista econômico, ou seja, que contribuam para a sustentabilidade da cadeia produtiva desse agronegócio (CARDOSO et al, 2015).

\section{GESTÃO DE RESÍDUOS SUÍNOS}

A utilização de um tratamento adequado para os resíduos promove uma redução no seu poder de poluição, atingindo concentrações de nutrientes e micro-organismos dentro dos padrões exigidos pelas leis ambientais, e permitindo sua utilização, por exemplo, nos solos (SANTOS et al., 2014).

Devido à elevada concentração de nutrientes nos resíduos da suinocultura, se estes forem devidamente manejados, poderão ser utilizados como fertilizantes na produção de alimentos; na melhora das condições físicas, químicas e biológicas do solo e, ainda, na geração de energia (MIRANDA et al., 2012).

As tecnologias e sistemas de tratamento, baseadas em processos físicos, químicos e biológicos, estão continuamente evoluindo e contribuindo para a produção de um efluente de melhor qualidade, com redução em diversos indicadores de poluição, como exemplos, Demanda Química de Oxigênio (DQO), Demanda Bioquímica de Oxigênio (DBO), sólidos totais, nitrogênio, fósforo, coliformes totais e termotolerantes (BELLI et al., 2001; VIANCELLI et al., 2013).

Belli et al. (2001) relataram que são poucas as granjas de suínos no Brasil que apresentam um sistema de tratamento, e nas que possuem, muitas vezes ele não é projetado, construído e nem operado de maneira adequada, gerando mais prejuízo do que benefícios. Infelizmente, nos dias atuais, isso ainda ocorre principalmente em regiões do país de menor uso do nível tecnológico.

Os estudos para o tratamento dos efluentes gerados pela criação suinícola devem levar em consideração a composição físico-química e microbiológica dos resíduos (CARIS et al., 2008). A composição do efluente gerado depende do sistema de manejo adotado, podendo apresentar grandes variações nas concentrações dos componentes, em função da diluição e do modo de manuseio e armazenamento utilizados (DAGA et al., 2007).

Geralmente, antes de submeter os resíduos gerados na suinocultura a algum tratamento específico, é realizada uma separação das frações sólida e líquida, a fim de melhorar a eficiência do processo (OLIVEIRA; FORESTI, 2004). Essa separação pode ser realizada utilizando processos como floculação, sedimentação, peneiramento e coagulação; e auxilia na redução do Tempo de Detenção Hidráulica (TDH) 
no posterior tratamento dos afluentes (KUNZ et al., 2010).

A decomposição da fase sólida geralmente é realizada em composteiras e, a parte líquida, pode ser condicionada e tratada em esterqueiras, bioesterqueiras, lagoas de estabilização, reator anaeróbio de fluxo ascendente com manta de lodo (Reator UASB) e biodigestores anaeróbios (PALÁCIO et al., 2012; SANTOS et al., 2015).

\subsection{Esterqueiras e Bioesterqueiras}

São considerados sistemas de armazenamento simples e com baixo custo de implantação, no qual os efluentes são condicionados em tanques por um período médio de 120 dias, para que bactérias, fungos e protozoários promovam a digestão anaeróbia da matéria orgânica, a qual poderá ser utilizada como fertilizante de acordo com as necessidades das culturas agrícolas (DIESEL et al., 2002).

Esses sistemas não são considerados como tratamento, pois não promovem uma redução significativa no poder poluente dos efluentes, não cumprindo os parâmetros exigidos pela legislação ambiental (MONTEIRO, 2005; SANTOS et al., 2014).

\subsection{Lagoas de estabilização}

São muito utilizadas no tratamento dos efluentes da suinocultura, apresentam baixo custo econômico, porém necessitam de grandes áreas para sua construção e um elevado tempo de detenção hidráulica (TDH). As lagoas anaeróbias são capazes de estabilizar efluentes com alta carga orgânica, reduzindo significativamente DBO e DQO. A ausência de gás oxigênio livre estimula a fermentação dos compostos orgânicos pelas bactérias facultativas e anaeróbias estritas. (MEDRI, 1997; PERDOMO; LIMA, 1998).

\subsection{Reator de fluxo ascendente com manta de lodo (UASB)}

Os reatores UASB são economicamente atraentes e apresentam facilidade construtiva e de operação, apresentando um baixo TDH no tratamento de águas residuárias com baixo teor de sólidos, como é o caso do efluente extremamente diluído da suinocultura (BELLI, 2001; SANTOS et al., 2014).

Esse tipo de reator apresenta separador de fases que o divide em duas partes, a inferior - que corresponde à manta de lodo na qual ocorre a digestão anaeróbia, e a superior -denominada zona de sedimentação. O separador permite a separação dos sólidos em suspensão da parte líquida e dos gases formados durante o processo. Os sólidos retornam para manta de lodo, e a parte líquida e os gases são mantidos na parte superior (MAGO, 2009).

\subsection{Biodigestor anaeróbio}

Biodigestores são reatores nos quais a matéria orgânica presente nos efluentes é metabolizada por micro-organismos anaeróbios. Nesse processo, as moléculas mais complexas são degradadas gerando outras mais simples, produzindo biogás que poderá ser utilizado como fonte alternativa de energia, e um efluente mais estabilizado química e microbiologicamente que poderá ser utilizado como biofertilizante e condicionador de solo (SILVA et al., 2012; GOMES et al., 2014; COSTA; SOTO, 2018). 


\subsection{Sistema de tratamento}

$\mathrm{Na}$ maioria das vezes os tratamentos isolados não são suficientes para adequar o efluente da suinocultura aos padrões estabelecidos pela legislação ambiental. Por isso, atualmente essas tecnologias são integradas gerando um sistema de tratamento (SANTOS et al.,2014).

O tratamento é realizado em etapas, tendo cada uma sua importância no resultado final do efluente. A primeira etapa corresponde ao tratamento preliminar que visa apenas remoção dos sólidos grosseiros, em seguida vem o tratamento primário que é utilizado para remoção de sólidos sedimentáveis e uma parte do material orgânico. Ambas utilizam predominantemente os mecanismos físicos para remoção dos poluentes. No tratamento secundário prevalecem os mecanismos biológicos visando remoção de material orgânico, e em menor proporção, nutriente. Por fim, o tratamento terciário, ou pós-tratamento, tem como objetivo a remoção complementar de nutrientes não removidos no tratamento secundário, além de poluentes tóxicos e compostos não biodegradáveis (BRANDÃO et al., 2000).

A maioria desses sistemas utiliza os mecanismos biológicos para uma remoção mais significativa dos poluentes, adotando geralmente para o tratamento secundário, a digestão anaeróbia devido às vantagens significativas que apresenta em relação aos processos aeróbios, tais como: ausência de equipamentos sofisticados, menor consumo de energia, baixa produção de lodo, produção de biofertilizante e biogás e alta eficiência na remoção de DBO (MORAES; PAULA, 2004; ANGONESE et al., 2007).

Uma alternativa atraente para o pós-tratamento são as lagoas de polimento ou maturação, pois estas são sistemas relativamente simples, facilitando o monitoramento e permitindo sua utilização por pequenos proprietários (MEDRI, 1997; SPERLING, 2002; CARMO et al., 2002). Nessas lagoas ocorre um tratamento aeróbio complementar, que oferece condições favoráveis para remoção de nutrientes (fósforo e nitrogênio) e patógenos (MEDRI, 1997; SPERLING, 2002; CAVALCANTI, 2003).

Como alternativa para os aeradores, estão sendo realizadas pesquisas utilizando macrófitas flutuantes para o tratamento de águas residuárias. A utilização dessas plantas no tratamento dos efluentes tem se destacado, pois além da capacidade de remover os nutrientes da água residuária, permite reciclar os nutrientes através de uma variedade de ações biológicas que ocorrem dentro do sistema da planta, da qual sua biomassa é rica em proteínas, permitindo sua utilização para alimentação animal, trazendo benefícios econômicos que podem suprir os gastos para implantação e manutenção do sistema de tratamento de dejetos (MOHEDANO, 2010).

\section{CONSIDERAÇÕES FINAIS}

A cadeia de produção na área da suinocultura possui um alto potencial de crescimento no cenário mundial, e o Brasil, com a sua figura emergente dentro das taxas de produção e exportação se destaca mesmo sem uma estruturação sólida da cadeia no país.

Além do crescimento de números de produção, esses avanços trouxeram diversos resultados, como o desenvolvimento de novos métodos, aprimoramentos genéticos, entre outros. No entanto, conforme discursado neste artigo, o crescimento dos efeitos negativos também foram aumentando ao decorrer dos anos, e hoje se tornou uma grande preocupação para os ambientalistas, pois suas ações implicam com a legislação brasileira de proteção ambiental.

A legislação possui leis rigorosas referente à poluição de ecossistemas, que aumentam sua gravidade de acordo com o grau de interferência nos meios bióticos e abióticos, e há uma diversidade de 
pontos negativos quando se trata dos dejetos gerados no processo da suinocultura, como por exemplo: poluição do solo, água e ar através das substâncias químicas, distribuição de animais patogênicos, proliferação de mosquitos e perda da biota local por poluição indesejada.

No entanto, as medidas mitigatórias destes problemas são de custo elevado para os produtores, causando um desequilíbrio entre o custo de produção e lucro, o que leva parte dos produtores a despejar os dejetos de forma inadequada, ignorando a legislação e os problemas ambientais. Como há muitos pequenos produtores, muitas vezes esses despejos passam despercebidos, sendo notado apenas em uma situação posterior muito mais além.

O equilíbrio entre a sustentabilidade e a renda da produção seria uma forma de incentivar os produtores a procurarem métodos onde o meio ambiente não seja afetado. Processos conjuntos, como biodigestores e bioesterqueiras, já estão sendo utilizadas no mundo, mostrando os melhores resultados diante de todos os métodos apresentados até hoje, e auxiliando o produtor não só no tratamento dos dejetos, como também, produzindo energia, biofertilizantes e, em alguns casos, como os das macrófitas aquáticas, alimentação para o ecossistema local. Desta maneira, a união entre a cadeia produtiva e o meio ambiente levaria a um caminho gradativamente mais natural, com tendência a ir cessando os problemas de grande preocupação.

As composteiras podem ser alternativas não só para grandes produtores que a utilizam com alta tecnologia, como também para os pequenos que não possuem recursos físicos e financeiros suficientes para manter a sustentabilidade do sistema.

O meio socioeconômico age sendo o maior problema na relação empreendedorismosustentabilidade da cadeia produtiva, mas com o auxilio de uma legislação mais fiscalizada, educação ambiental aos envolvidos e oportunidades como empréstimos, financiamentos e ajudas de custo para a implantação dos processos de valor alto para os pequenos suinícolas, teria um resultado positivo não só para o meio ambiente, como também para o produtor, que trabalharia de acordo com as leis, evitando assim multas e outras penas, e teria a possibilidade de aumentar os rendimentos da cadeia com uma sustentabilidade ambiental e econômica.

\section{BIBLIOGRAFIA}

ABREU, M. S.; OLIVEIRA, R. A. Remoção de matéria orgânica, de nutrientes e de coliformes no processo anaeróbio em dois estágios (reator compartimentado seguido de reator UASB) para o tratamento de águas residuárias de suinocultura. Engenharia Agrícola, v. 29, n. 1, p.148-161, 2009.

ALBUQUERQUE, A. L.; WEYDMANN, C. L. Avaliação da regulação ambiental para suinocultura: comparação entre os principais estados produtores. Acesso em out. 2015, <http://www.apec.unesc.net/I\%20EEC/sessoes_tematicas/Desenvolvimento_Meio/artigo2. PDF>.

ANGONESE, A.R; CAMPOS A. T.; WELTER, R. A. Potencial de redução de emissão de equivalente de carbono de uma unidade suinícola com biodigestor. Engenharia Agrícola, v. 27, n. 3, p. 48-657, 2007.

ASSOCIAÇÃO BRASILEIRA DE PROTEÍNA ANIMAL - APBA. Relatório Anual, 2018. Disponível em: < http://abpa-br.com.br/storage/files/relatorio-anual-2018.pdf>. Acesso em: 15 ago. 2019.

BELI E.; HUSSAR, G.J.; HUSSAR, D. H. Redução de DQO e turbidez de efluente de uma unidade suinícola empregando Reator Anaeróbio Compartimentado (RAC) seguido de filtro biológico e filtro de areia. Engenharia Ambiental, v. 7, n. 1, p.5-19, 2010. 
BELLI, P.et al. Tecnologias para o tratamento de dejetos de suínos. Revista Brasileira de Engenharia Agrícola e Ambiental, v. 5, n. 1, p. 166-170, 2001.

BRANDÃO, V. S.et al.Tratamento de águas residuárias da suinocultura utilizando-se filtros orgânicos. Revista Brasileira de Engenharia Agrícola e Ambiental, v. 4, n. 3, p. 327-333, 2000.

BRASIL. Constituição da República Federativa do Brasil, de 5 de outubro de 1988. Brasília, DF: Senado, 1988. Acesso out. 2017, <http://www.planalto.gov.br/ccivil_03/Constituicao/ ConstituicaoCompilado.htm>.

BRASIL. Decreto n. ${ }^{\circ} 7404$ de 23 de dezembro de 2010. Regulamenta a Lei no 12.305, de 2 de agosto de 2010, que institui a Política Nacional de Resíduos Sólidos, cria o Comitê Interministerial da Política Nacional de Resíduos Sólidos e o Comitê Orientador para a Implantação dos Sistemas de Logística Reversa, e dá outras providências. Brasília, DF. Acesso out. 2015, <http://www.planalto.gov.br/ccivil_03/_Ato2007-2010/2010/Decreto/ D7404.htm>.

BRASIL. Lei n. ${ }^{\circ} 6938$ de 31 de agosto de 1981. Dispõe sobre a Política Nacional do Meio Ambiente, seus fins e mecanismos de formulação e aplicação, e dá outras providências. Brasília, DF. Acesso out. 2015. <http://www.planalto.gov.br/ccivil_03/Leis/L6938 compilada.htm>.

BRASIL. Lei n. ${ }^{\circ} 9433$ de 08 de janeiro de 1987. Institui a Política Nacional de Recursos Hídricos, cria o Sistema Nacional de Gerenciamento de Recursos Hídricos, regulamenta o inciso XIX do art. 21 da Constituição Federal, e altera 0 art. $1^{\circ}$ da Lei $n^{\circ} 8.001$, de 13 de março de 1990, que modificou a Lei $\mathbf{n}^{0}$ 7.990, de 28 de dezembro de 1989. Brasília, DF.

Disponível em: <http://www.planalto. gov.br/ccivil_03/Leis/L9433.htm >. Acesso em: out. 2015.

BRASIL. Lei n. $^{\circ} 9605$ de 12 de fevereiro de 1998. Dispõe sobre as sanções penais e administrativas derivadas de condutas e atividades lesivas ao meio ambiente, e dá outras providências. Brasília, DF. Disponível em: <http://www.planalto.gov.br/ccivil_03/LEIS/L9605.htm>. Acesso em: out. 2015.

BRASIL. Lei n. ${ }^{\circ} 12.305$ de 02 de agosto de 2010. Institui a Política Nacional de Resíduos Sólidos; altera a Lei $n^{0}$ 9.605, de 12 de fevereiro de 1998; e dá outras providências. Brasília, DF. Disponível em:<http://www.planalto.gov.br/ccivil_03/_Ato20072010/2010/ Lei/ L12305.htm >.Acesso em: out. 2015.

BRASIL. Resolução CONAMA no 001, de 23 de janeiro de 1986. Disponível em: <http://www.mma.gov.br/port/conama/res/res86/res0186.html>. Acesso em: out. 2015.

BRASIL. Resolução CONAMA n 237, de 19 de dezembro de 1997. Disponível em: <http://www.mma.gov.br/port/conama/res/res97/res23797.html>. Acesso em: out. 2015.

BRASIL. Resolução CONAMA no 357, de 17 de março de 2005. Disponível em: <http://www.mma.gov.br/port/conama/res/res05/res35705.pdf >. Acesso em: out. 2015.

BRASIL. Resolução CONAMA no 430, de 13 de maio de 2011. Disponível em: <http://www.mma.gov.br/port/conama/legiabre.cfm?codlegi=646>. Acesso em: out. 2015.

BRASIL. Sumário Mineral 2014. Departamento Nacional de Produção Mineral, Brasília, 2014.

CAMPOS, C. M. M.; MOCHIZUKI, E. T.; DAMASCENO, L. H. S.; BOTELHO, C. G. Avaliação do potencial de produção de biogás e da eficiência de tratamento do reator anaeróbio de manta de lodo (UASB) alimentado com dejetos de suínos. Ciência e Agrotecnologia, v. 29, n. 4, p. 848-856, 2005.

CARIS, M.E.; ANDRADE, A.S.P.; PHILIPPI, L.S. Determinação do potencial de biorremediação de nutrientes e bioindicação de águas residuárias da suinocultura por macrófitas flutuantes (Lemma minuta) Efeito de altas taxas de nitrogênio amoniacal. Evidência - Ciência e Biotecnologia, v. 8, n.1-2, 85-102, 2008. 
CAVALCANTI, P.F.F. Integrated application of the uasab reactor and ponds for domestic sewage treatment in tropical regions. 2003. 139p.

CARDOSO, B. F.; OYAMADA, G. C.; SILVA, C. M. Produção, tratamento e uso dos dejetos suínos no Brasil. Desenvolvimento em Questão, v.13, n.32, p. 127-145, 2015.

CARVALHO, B. V., SOUZA, A. P. M., SOTO, F. R. M. Avaliação de sistemas de gestão ambiental em granjas de suínos. Revista Ambiente e Água, v. 10, n. 1, p.164-171, 2015.

CIAS - Central de Inteligência de Aves e Suínos. A suinocultura no Brasil. Disponível em: $<$ http://www.cnpsa.embrapa.br/cias/index.php?option=com_content\&view=article\&id=5:origem-dossuinos\&catid=4: suinos-publico\&Itemid=19>. Acesso em: out. 2015.

COSTA, A. A.; SOTO, F. R. M. Tratamento do dejeto de suíno por biodigestão anaeróbia. Revista em Agronegócio e Meio Ambiente, v.11, n.3, p.801-823, 2018.

DAGA, J.et al. Análise da adequação ambiental e manejo dos dejetos de instalações para suinocultura em propriedades na região oeste do Paraná. Engenharia Agrícola, v. 27, n. 3, p. 587-595, 2007.

DIESEL, R; MIRANDA C. R; PERDOMO, C. C. Coletânea de tecnologias sobre dejetos suínos, Boletim Informativo Pesquisa \& Extensão-BIPERS, ANO 10, nº 14,2002, Embrapa Suínos e Aves e Extensão-EMATER/RS. Disponivel em: < http://docsagencia.cnptia.embrapa.br/suino/bipers/bipers14.pdf>. Acesso em: fev. 2018.

FERNANDES, G.F.R; OLIVEIRA, R.A. Desempenho de processo anaeróbio em dois estágios (reator compartimentado seguido de reator UASB) para tratamento de águas residuárias de suinocultura. Engenharia Agrícola, v. 26, n.1, p.243-256, 2006.

GOMES, L.P.et al. Indicadores de sustentabilidade na avaliação de granjas suinícolas. Engenharia Sanitária Ambiental, v. 19, n.2, p. 143-154, 2014.

IBGE - Instituto Brasileiro de Geografia e Estatística. Indicadores IBGE: Estatística da Produção Pecuária - Junho de 2016. 2017. Disponível em: <

ftp://ftp.ibge.gov.br/Producao_Pecuaria/Fasciculo_Indicadores_IBGE/2016/abate-leite-couroovos_201601caderno.pdf>. Acesso em: out. 2016.

KONZEN, E. A. Viabilidade ambiental e econômica de dejetos de suínos. Sete Lagoas: Embrapa Milho e Sorgo, 2006. 25 p.

KUNZ, A.; STEINMETZ, R. L. R.; BORTOLI, M. Separação sólido-líquido em efluentes da suinocultura. Revista Brasileira de Engenharia Agrícola e Ambiental, v. 14, n. 11, p. 1220-1225, 2010.

LOPES, C. R. M.; FILHO, N. R. A.; ALVES, M. I. R. Enciclopédia Biosfera, v. 9, n.17, p. 3556 - 3565.

MAGO, A. Avaliação de biodigestores com o uso de dejetos de suínos, em Braço do Norte e em Concórdia. Florianópolis, 2009. 152p. Dissertação de Mestrado - Programa de Pós-Graduação em Engenharia Ambiental - Universidade Federal de Santa Catarina.

MEDRI, W. Modelagem e otimização de lagoas de estabilização para tratamento de dejetos suínos. Florianópolis, Tese (Doutorado em Engenharia de Produção, Universidade Federal de Santa Catarina, 1997.

MIRANDA, C.R. Aspectos Ambientais da suinocultura brasileira. In: Seganfredo, M.A. Gestão Ambiental na Suinocultura. Brasília: Embrapa Informação Tecnológica, p. 13-36, 2007. 
MIRANDA, C.R. O Termo de Ajustamento de Condutas da suinocultura da região do alto uruguai catarinense. In: Miranda, C.R.; Miele, M. Suinocultura e Meio Ambiente em Santa Catarina:

Indicadores de desempenho e avaliação socioeconômica. Concórdia: Embrapa Suinos e Aves, p. 137-176, 2009.

MIRANDA, A.P.et al. Anaerobic biodigestion of pig feces in the initial, growing and finishing stages fed with diets formulated with corno r sorghum. Engenharia Agrícola, v.12, n.1, p. 47-59, 2012.

MONTEIRO, L. W. S. Avaliação do desempenho de dois sistemas em escala real para o manejo dos dejetos suínos: Lagoa armazenamento comparada com biodigestor seguido de lagoa de armazenamento. Florianópolis, 2005. 146p. Dissertação de Mestrado - Programa de Pós-Graduação em Engenharia Ambiental - Universidade Federal de Santa Catarina.

MOHEDANO, R.A. Uso de macrófitas lemnáceas (Landoltiapuctata) no polimento e valorização do efluente de suinocultura e nafixação de carbono. Florianópolis, Tese (Doutorado em Engenharia Ambiental), Universidade Federal de Santa Catarina, 2010.

MORAES, L.M.; PAULA, D.R. Avaliação da biodegradabilidade anaeróbia de resíduos da bovinocultura e da suinocultura. EngenhariaAgrícola, v.24, n.2, p. 445-454, 2004.

OCDE - ORGANIZATION FOR ECONOMIC CO-OPERATION AND DEVELOPMENT. Agriculture Trade and the Environment: the Pig Sector. Disponível em: <http://oecd.org/bookshop>. Acesso em: set 2015.

OLIVEIRA, R.A.; FORESTI, E. Balanço de massa de reatores anaeróbios de fluxo ascendente com manta de lodo (UASB) tratando águas residuárias de suinocultura. Engenharia Agrícola, v. 24, n. 3, p. 807-820, 2004.

OLIVEIRA, R.A.; DUDA, R.M.; FERNANDES, G.F.R. Reator anaeróbio compartimentado para o tratamento de águas residuárias de suinocultura. Engenharia Sanitária Ambiental, v. 19, n.4, p. 383$391,2014$.

PALÁCIO, S.M.et al. Degradação de resíduos orgânicos provenientes da suinocultura empregando o processo de bioaumentação. Engevista, v. 14, n. 2, p. 155-164, 2012

PALHARES, J.C.P.; CALIJURI, M.C. Impacto de sistemas de produção suinícola na qualidade dos recursos hídricos. Concórdia: Embrapa Suínos e Aves, 2006.

PALHARES, J.C.P. Legislação ambiental e suinocultura: Barreiras, leis e futuro. In: SEGANFREDO, M.A. Gestão Ambiental na Suinocultura. Brasília: Embrapa Informação Tecnológica, p.37-62, 2007.

PALHARES, J. C. P. Licenciamento Ambiental na Suinocultura: os Casos Brasileiro e Mundial. Concórdia, (SC): Embrapa Suínos e Aves, 2008.

PERDOMO, C.C.; LIMA, G.J.M.M. Considerações sobre a questão dos dejetos e o meio ambiente. In: Sobestiansky, J. et al. Suinocultura Intensiva: Produção, Manejo e Saúde do Rebanho. Brasília: Embrapa-SPI, p. 221-235, 1998.

PERDOMO, C.C. Sugestões para o manejo, tratamento e utilização de dejetos suínos. Concórdia: Embrapa Suínos e Aves, 1998. (Instrução e técnica para o Suinocultor, 12). Disponível em: <http://www.ufrgs.br/preventiva/itsu012.pdf>. Acesso em: mar. 2016.

SÁ, M. F.et al. Dinâmica da população de coliformes durante a compostagem automatizada de dejetos líquidos de suínos. Arquivo Brasileira de Medicina Veterinária e Zootecnia, v. 66, n. 4, p.1197-1206, 2014. 
SANTOS, L.D.; MAYERLE, S.F.; CAMPOS, L.M.S. Tecnologias e sistemas de tratamento para os dejetos da suinocultura. Revista Verde de Agroecologia e Desenvolvimento Sustentável, v. 9, n.5, p. 12$18,2014$.

SANTOS, L. D.et al. Sistema produtivo suinícola: abordagens biológica, de processos, sistêmica e logística. Revista Eletrônica em Gestão, Educação e Tecnologia Ambiental, v. 19, n. 2, p. 266-280, 2015.

SESTI, L.A.C.; SOBESTIANSKY, J. Aspectos da Produtividade. In: SOBESTIANSKY, J. et al. Suinocultura Intensiva: Produção, Manejo e Saúde do Rebanho. Brasília: Embrapa-SPI, 1998, cap.2, p. 27-44.

SILVA, W. T. L.et al. Avaliação físico-química de efluente gerado em biodigestor anaeróbio para fins de avaliação de eficiência e aplicação como fertilizante agrícola. Química Nova, v. 35, n. 1, p. 35-40, 2012.

SOUZA, J.A.R.et al. Variação do nitrogênio e fósforo em solo fertirrigado com efluente do tratamento primário da água residuária da suinocultura. Revista Ambiente e Água, v.4, n.3, p.111-122, 2009.

SPIES, A. Avaliação de impactos ambientais da suinocultura através da análise do ciclo de vida - ACV. In: Miranda, C.R.; MIELE, M. Suinocultura e Meio Ambiente em Santa Catarina: Indicadores de desempenho e avaliação socioeconômica. Concórdia: Embrapa Suinos e Aves, p. 13-44, 2009.

SPERLING, M. Von. Lagoas de estabilização. Princípios do tratamento biológico de águas residuárias. 2.ed. Belo Horizonte: DESA - UFMG, p. 240, 2002.

URBINATI, E.; DUDA, R. M.; OLIVEIRA, R. A. Performance of UASB reactors in two stages under different HRT and OLR treating residual waters of swine farming. Engenharia Agrícola, v. 33, n. 2, p. 367-378, 2013.

VIANCELLI, A.et al. Performance of two swine manure treatment systems on chemical composition and on the reduction of pathogens. Chemosphere, v. 90, n. 4, p. 1539-1544, 2013.

ZANOTELLI, C.T. Modelagem matemática de nitrogênio e fósforo em lagoas facultativas e de aguapés para tratamento de dejetos de suínos. Florianópolis, Tese (Doutorado em Engenharia de Produção, Universidade Federal de Santa Catarina, 2002. 